\title{
A Simplified Assay Method for Determining the Binding Affinities of DNA Binding Molecules to Duplex DNA
}

\author{
Hyun Hye Jang, Sujung Yi, Mi Hee Kim, Sudeok Kim, Na Hee Lee, Min Sik Eom, and Min Su Han' \\ Department of Chemistrv. Chung-Ang Lnwersin, Seoul 156-756. Korea. E-mail: mshaniácauac.hr \\ Received Algust 28, 2009. Accepted October 14, 2009
}

Key Words: Gold nanoparticles, Anticancer. Assay, DNA, High throughput screen

Chemotherapy is a crucial anticancer strategy. Numerous compounds have been developed as potential candidates for anticancer dnig. and many of these compounds. including FDAapproved anti-cancer drugs such as doxorubicin. daunorubicin and amsacrine are known to reversibly interact with DNA to form drug/DNA complexes. 'Large libraries of compounds of DNA-binding molecules have been synthesized by combinatorial chemistry " However the selection of viable candidates among the many compounds contained in these libraries is one of the major bottlenecks in drug discovery ${ }^{3}$ To overcome this problem, hugh-throughput screenung (HTS) methods are used to screen large libraries of potential drug candidates for biological activity. ${ }^{4}$ Generally, the anticancer drug s biological activity is correlated with its binding affinities to DNA. ${ }^{5}$ In the past, typical screening processes have included mass spectroscopy. nuclear magnetic resonance, light scattering. and electrochemistry. ${ }^{6} \mathrm{Un}$ fortunately these methods are not applicable to HTS. Only recently have hugh-throughput compatible fluorescence screening protocols been developed. Despite being useful tools, fluorescent intercalator displacement (FID) assays have some weaknesses. The FID is an on-off system and the fluorescent signal of the reference intercalator (thuazole orange or ethidium bromide (EB)) often interferes with that of the DNA binding molecule of interest. ${ }^{8}$

Recently, Mirkin et al. reported high-throughput compatible colorimetric detection of the relative binding affinities of binding molecules to DNA using DNA-functionalized gold nanoparticles. ${ }^{9}$ This method is more practical and simpler than conventional methods except for the requirement of raising the temperature during the detection process. This makes the system relatively costly and somewhat impractical for HTS.

In this paper. we describe a simple new colorimetric assay for determuming the relative binding affinities of DNA binding molecules to duplex DNA. It incorporates DNA-functionalized

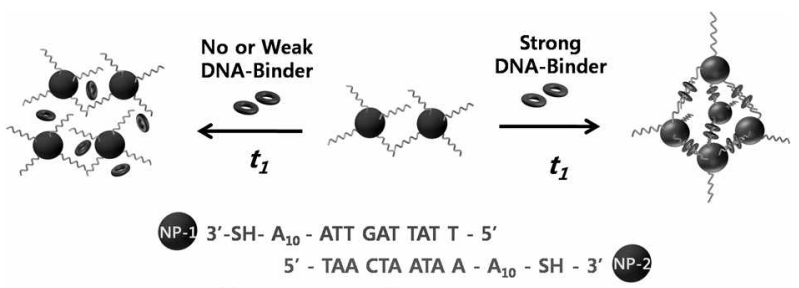

Scheme 1. Schematic representation of structure and color changes of nanoparticle/DNA binding molecule assemblies at specific times. $t_{2}$ represents time gold nanoparticles without the need for instrumentation such as temperature controllers. This new method relies on the kinetics of polymeric aggregates of DNA-functionalized gold nanoparticles (DNA-AuNPs) in the presence of DNA binding molecules. The kinetics is very sensitive to factors such as salt concentration and buffer $\mathrm{pH}$. The density of DNA on gold nanoparticles caused by the aggregation of DNA-AuNPs is dependent on the binding affinities betreen each conplementary DNA on those nanoparticles. ${ }^{11}$ Therefore. we assumed that the kinetics of aggregation of DNA-AuNPs were dependent on the species and concentration of DNA binding molecules because such molecules enhance the stability of duplex DNA.

Gold nanoparticles were prepared by functionalizing two separate batches of $13 \mathrm{~nm}$ gold particles with two different thiol-modified oligonucleotide strands: DNA-I and DNA-2. When DNA-binding molecules such as 4'.6-diamidino-2-phemylindone (DAPI) are added to solutions containing AuNP-I and AuNP-2 (1.5 nM each, $3.0 \mathrm{nM}$ total Au NP). they bind to the duplex DNA interconnects linking the nanoparticles and stabilize the duplex DNA. Fig. 1 demonstrates that these additional binding interactions decrease the time required for the AuNPs to aggregate. This suggests that the kinetics of polymenc aggregates of AuNPs is very sensitive to the interactions between DNA binding molecules.

Next, we determined the relative affinities of vanous DNA binding molecules to duplex DNA by evaluating the kinetics of AuNP aggregation in the presence of the molecules. In a typical assay, a DNA binding molecule such as anisacrine (AMSA), anthraquinone-2-carboxylic acid (AQ2A), 9-ammoacndine (9-

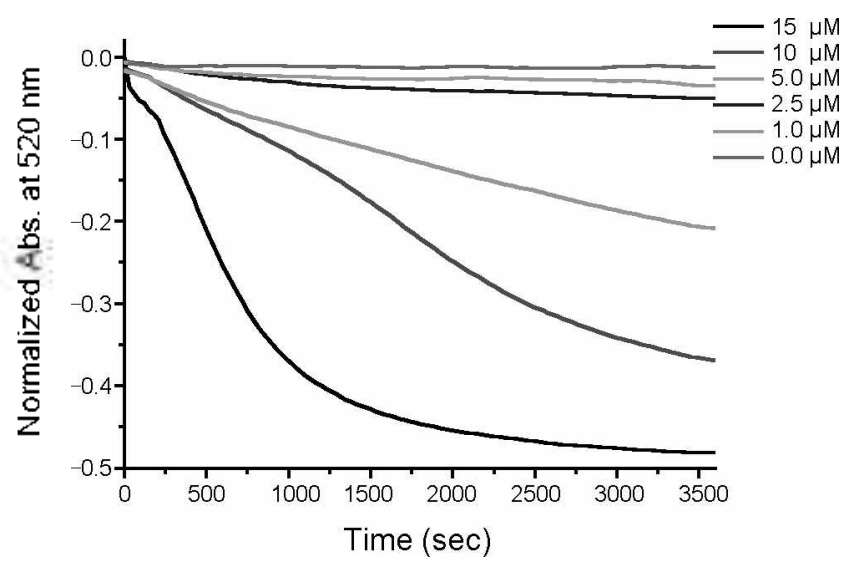

Figure 1. Kinetics for aggregates of NP-1 and NP-2 with different concentrations of DAPI in $10 \mathrm{mM}$ SPB solution $(\mathrm{pH} 7.0, \mathrm{NaCl} 0.15 \mathrm{M})$. 
(a)

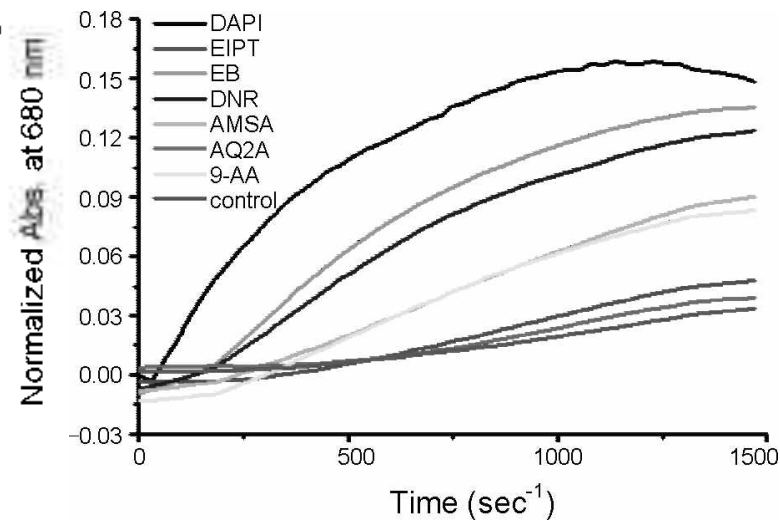

(b)

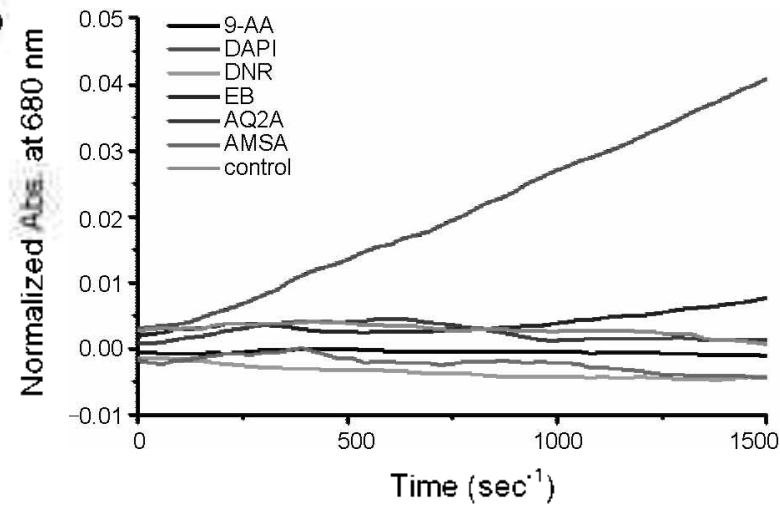

Figure 2. The kinetics of the AuNP aggregation process in the absence and presence of DNA binding molecules at different concentrations of $\mathrm{NaCl}$ (a) $0.2 \mathrm{M}$ (b) $0.15 \mathrm{M}$. The changes in extinction were monitored at $680 \mathrm{~nm}$.

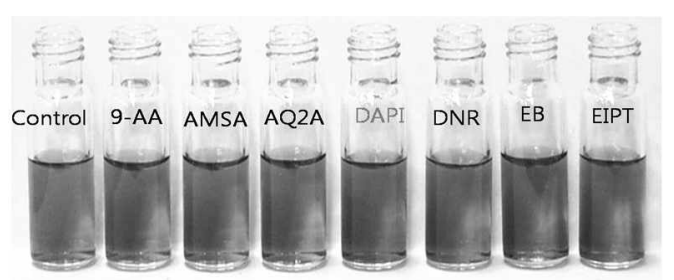

Figure 3. Color changes in gold nanoparticle substrates 45 minutes after the addition of DNA binding molecules.

AA), ellipticine (EIPT), daunonibicin (DNR), ethidium bromide (EB) or t', 6-diamidedino-2-phenylindole (DAPI), $5 \mu \mathrm{M}$ is added to mixture solutions of AllNP-I (1.5 nM) and AuNP-2 $(1.5 \mathrm{nM})$ in SPB buffer with $0.2 \mathrm{M} \mathrm{NaCl}$. The absorbance change of the mixture is monitored at $620 \mathrm{~nm}$ as a function of time (sample scan rate: $30 \mathrm{~s}^{-1}$ ). The DNA binding molecules stabilize the duplex DNA interconnects linking the nanoparticles and decrease the time required for poly'meric aggregates of DNA-AuNPs to form, i.e. the time it takes for the solution to change color. Thus. we can deternine the relative binding affinities of DNA binding molecules by measuring the color-change time. Fig. 2 demonstrates the relationships between aggregation times such that DAPI $<$ EB $\sim$ DNR $<9$-AA. EIPT, AQ2A, and AMSA. which is almost consistent with the relative binding affinities of these molecules to DNA. ${ }^{9}$ However, without UV-Vis spectrometry, it is very hard to discriminate between the relative binding affinities of DNA molecules. Because the stability of DNA duplexes is increased by salt. we expected that the time required for AuNPs to aggregate would be more sensitive to the relative binding affinities of DNA molecules at lower salt concentrations. At decreased salt concentrations $(0.15 \mathrm{M} \mathrm{NaCl})$. despite the effects of EB on the time required for AuNPs to aggregate, the assay proved to be specific for identifying the strongest DNA binder in these molecules. DAPI can be identified by a color change of AuNP solution from red to blue. Although the method with a temperature controller can more precisely discriminate the relative binding affinities of DNA binding molecules to DNA than our method, the method need an incubation time to form an aggregate of DNA-AuNPs for deternining the relative binding affinities. "While, our method doesn't need any incubation time to deternine the relative binding affinities because of monitoring the color change of DNA-AuNPs. exposed to the DNA binders. over time intervals.

HTS is now widely used for identification of hit conpounds from combinatorial libraries. ${ }^{4}$ We have examined the application of gold nanoparticles for HTS of DNA binding molecules through visual inspection. DNA binding molecules possessing strong binding affinities cause the color of AuNP solutions to clange rapidly from purple to red. An absent or slow color change indicates weak binding affinities. Thus. we can use color change as a function of time to deternine the relative binding affinities of DNA molecules. Figure 3 shows that DAPI in the DNA binding molecules is strongest, which allows the identification of the strongest binder in various DNA binding molecules.

In summary, we have developed a colorimetric assay for determining the relative binding affinities of molecules to duplex DNA by monitoring color changes in DNA-AuNPs exposed to DNA binders over various intervals of time. Although the assay cannot precisely determine the binding affinities of molecules to duplex DNA, it is simpler to apply than conventional systems that monitor molecule-DNA interactions directly or AuNP probes based upon temperature control. In addition, this assay can be easily adapted to HTS methods. which can then be used to identify' potential anti-cancer agents within large combinatorial libraries. based on their duplex DNA binding affinities.

Acknowledgments. This work was supported by the ChungAng University (2009)

\section{References}

1. Yang. X.-L.: Wang. A. H.-T. Phama. Therap. 1999, 83, 181

2. Boger, D. L. Fink, B. E; Hedrick, M. P. J.Am. Chem Soc $\mathbf{2 0 0 0 ,}$ 122,6382 .

3. Walker, M. T. A.; Barrett, T.; Guppy, L. T. Torgets 2004, 3, 208.

4. Jolnston, P. A., Johnston, P. A. Drig Discov. Todav 2002, $7,353$.

5. Reha. D.: Kabelac. M.: Ryjacek. F.: Sponer. T.: Sponer. J. E.: Elstrer, M.; Suhai, S.; Hobza, P. J. Ant. Chent. Soc. 2002, 124, 3366.

6. (a) Hofstadler, S. A.; Griffer, R. H. Chent. Rev 2001, 101, 377. (b) Robinson, H.; Priebe, W.: Chaires, J. B.; Wang, A. H.-J Biochemistv 1997. 36. 8663. (c) Pasternack. R. F.: Bustamante. C.: Collings. P. J.; Giannetto, A.; Gibbs, E. T. J. Am. Chent. Soc. 1993, 115, 5393. (d) Li, C.-Z.; Liu, Y.; Luong, H. T. Anal Chemt 2005, $77,478$.

7. Boger, D. L.: Fink, B. E.; Brunette, S. R.; Tse, W. C.: Hedrick, M. P. J. Am. Chem. Soc. 2001, 123, 5878 .

8. Haugland, R. P. Hantbook of Fluorescent Probes and Research Prodtuct; Molecular Probes, Eugene, Or, 2002.

9. Han, M. S.; Lytton-Tean, A. K. R.; Oh, B.-K.; Heo, J ; Mirkin, C. A. Angew. Chem Intl Ed. 2006, $45,1807$.

10. Jin, R.: Wu, G.: Li, Z.: Mirkin, C. A.: Schatz, G. C. J. Am. Chem. Soc. 2003, 125,1643 . 